\title{
Effect of temperature on the physical, optical and photocatalytic properties of $\mathrm{TiO}_{2}$ nanoparticles
}

\author{
Luciano Velardi $^{1}$ (1) $\cdot$ Luigi Scrimieri $^{1,2} \cdot$ Antonio Serra $^{1} \cdot$ Daniela Manno $^{1} \cdot$ Lucio Calcagnile $^{1}$
}

Received: 3 December 2019 / Accepted: 16 March 2020 / Published online: 19 March 2020

(c) Springer Nature Switzerland AG 2020

\begin{abstract}
In this paper we describe the effect of calcination temperature on the structural, morphological, optical and photocatalytic properties of $\mathrm{TiO}_{2}$ nanoparticles. The titanium dioxide powders were produced by the sol-gel method starting from titanium tetraisopropoxide (TTIP) in neutral aqueous medium (pH 5.5). After that, the $\mathrm{TiO}_{2}$ nanoparticles were treated at three different calcination temperatures for $4 \mathrm{~h}: 100,450$ and $800^{\circ} \mathrm{C}$. Then, the powders were characterized by XRD, Raman and photoluminescence techniques. We observed the anatase phase for the powders treated at 100 and $450^{\circ} \mathrm{C}$ and rutile for that treated at $800^{\circ} \mathrm{C}$. The photocatalytic activity of the $\mathrm{TiO}_{2}$ powders was investigated using Methylene Blue test and showed a strong correlation with the temperature (i.e. $\mathrm{TiO}_{2}$ phase). The better photocatalysis exhibited by the nanoparticles treated at 100 and $450^{\circ} \mathrm{C}$ compared to the powder at $800^{\circ} \mathrm{C}$ was due to the higher recombination of photo-generated electrons and holes of rutile with respect to anatase.
\end{abstract}

Graphic abstract
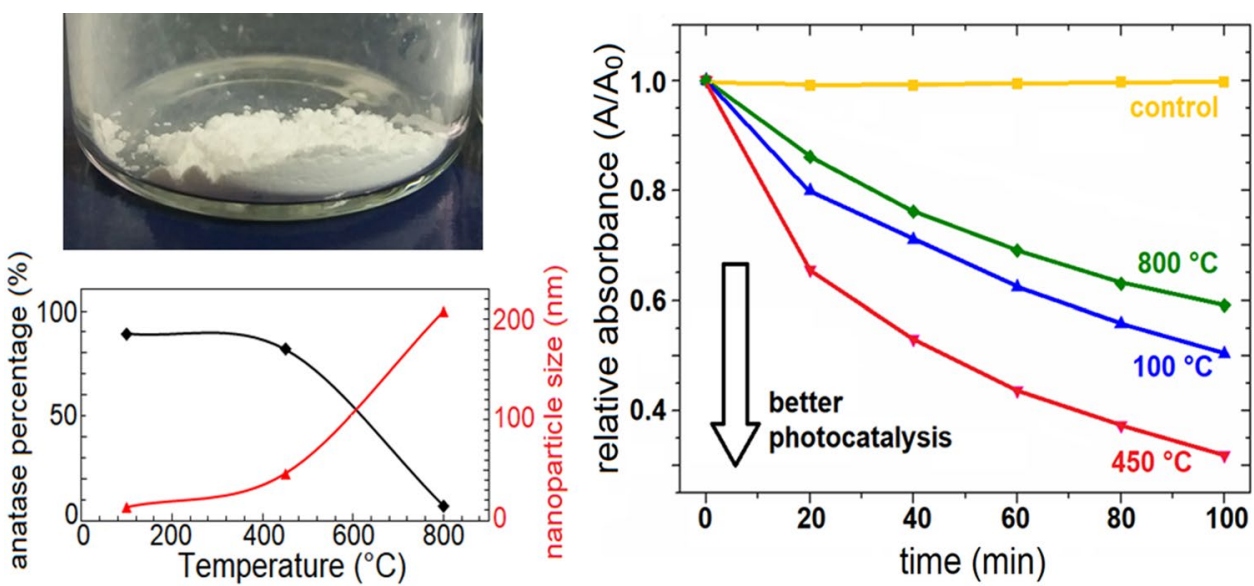

Keywords Sol-gel $\cdot \mathrm{TiO}_{2} \cdot$ Nanoparticles $\cdot$ Calcination temperature $\cdot$ Photocatalysis

Luciano Velardi, luciano.velardi@le.infn.it | ${ }^{1}$ Department of Mathematics and Physics, CEDAD - CEnter of Applied Physics, DAting and Diagnostics, University of Salento, Lecce, Italy. ${ }^{2}$ Department of Engineering for Innovation, University of Salento, Lecce, Italy. 


\section{Introduction}

Titanium dioxide is a well known wide-bandgap semiconductor and when irradiated by light of a wavelength equal to or greater than the energy band gap, generates electron-hole pairs, capable of inducing oxide-reduction reactions that underlie the processes of photocatalysis. Since the discovery of electrochemical photolysis of water mediated by a $\mathrm{TiO}_{2}$ electrode in 1972 by Fujishima and Honda [1], the interest in this material has grown enormously [2]. It is an extremely versatile material; it can in fact be synthesized in different modes (nanoparticles, film, nanorod, nanopore arrays, bulk) by chemical or physical processes, at low temperature and with low production costs. By virtue of its characteristics, it has found applications in various fields, from the energy one for the production of solar cells [3] to the environmental one, in particular in the degradation of organic pollutants [4]. It is also used in the production of coatings with antibacterial properties [5-8] or with self-cleaning capabilities [9].

It is possible to modify the characteristics of this material by acting on the temperature [10-12]: this induces modifications in terms of crystalline phase composition, optical properties, state of aggregation and nanoparticle size. All these aspects are of fundamental importance because affect the photocatalytic properties $[5,9,10$, 13-15] of the $\mathrm{TiO}_{2}$ surface.

This work takes in consideration simultaneously the effect of temperature on the phase composition, degree of crystallinity, dimension of nanoparticles, optical properties and photocatalytic activity of $\mathrm{TiO}_{2}$ nanoparticles produced by sol-gel method. The obtained powders were thermally treated at three different temperatures of 100,450 and $800^{\circ} \mathrm{C}$ and then characterized by XRD, Raman and photoluminescence $(\mathrm{PL})$ techniques. The photocatalytic activity of the $\mathrm{TiO}_{2}$ powders, evaluated using methylene blue as a model dye, showed also a strong correlation with the $\mathrm{TiO}_{2}$ phase.

\section{Materials and methods}

\subsection{Synthesis}

The $\mathrm{TiO}_{2}$ nanoparticles were synthesized by the sol-gel method starting from a volume of $3 \mathrm{~mL}$ of titanium tetraisopropoxide ( $\geq 97 \%$, TTIP) dissolved in $20 \mathrm{~mL}$ of ultrapure water milliQ grade. In these conditions, the $\mathrm{pH}$ of the sol resulted 5.5. All the chemicals used were procured from Sigma-Aldrich. Then, the reagents were magnetically stirred for $1 \mathrm{~h}$ and then left for the aging process in dark for $24 \mathrm{~h}$. The sols were transformed into gels and the deposits obtained at the bottom of the containers were washed and collected two times with ethanol ( $\geq 99.8 \%$ ) and other two times with ultrapure water, in an orbital shaker. After that, the products were dried oven for $3 \mathrm{~h}$ at $70^{\circ} \mathrm{C}$, to get a fine powder. The obtained powders were then calcined for $4 \mathrm{~h}$ at three different calcination temperatures $\mathrm{T}=100,450$ and $800{ }^{\circ} \mathrm{C}$ in a muffle furnace.

\subsection{Characterization}

The crystalline phase composition, the chemical-structure characteristics and the optical properties of the titania powders were assessed by XRD, Raman and photoluminescence techniques, respectively. The samples to be characterized were prepared as $\mathrm{TiO}_{2}$ pellets starting from $200 \mathrm{mg}$ of powder and pressed in a $13 \mathrm{~mm}$ Evacuable Pellet Die under a load of 10 tons using a manual hydraulic press.

The XRD investigation was performed by a Rigaku Miniflex diffractometer, in step-scan mode over the $2 \theta$ range of $10^{\circ}-80^{\circ}\left(0.010^{\circ}\right.$ step size and scan speed of $\left.0.25^{\circ} \mathrm{min}^{-1}\right)$ using Cu-Ka radiation ( $\lambda=0.154 \mathrm{~nm})$ at $30 \mathrm{kV}$ and $100 \mathrm{~mA}$.

The Raman measurements were carried out at room temperature using an InVia spectrometer type Renishaw PLC, Gloucestershire, UK equipped with an optical Leica microscope. The spectra were collected using an $\mathrm{Ar}^{+}$ions laser ( $514.5 \mathrm{~nm}$ exciting line) working at a maximum output power of $25 \mathrm{~mW}$ and recorded with a resolution of $1.5 \mathrm{~cm}^{-1}$ in spectral range $100-1000 \mathrm{~cm}^{-1}$.

The photoluminescence spectra were obtained in backscattering configuration, at room temperature and in air using as excitation source a monochromic light from a $375 \mathrm{~nm} 70 \mathrm{~mW}$ Spectra-Physics laser (the corresponding photon energy is $3.31 \mathrm{eV}$ ). The PL light was collected by a thin lens ( $5 \mathrm{~cm}$ of focal length) on a computer-controlled monochromator type TRIAX 320 equipped with two diffraction gratings with 1200 and 1800 grooves. As CCD detector, a liquid nitrogen cooled Symphony Detection System (2048 element linear CCD array) was used. An optical longpass filter was also utilized to reduce the laser light and to collect only the laser-induced luminescence.

In order to evaluate the photocatalytic activity of titanium dioxide powders, methylene blue (MB) degradation tests were conducted under UV light. Experiment was carried out in quartz cuvettes: $1 \mathrm{mg}$ of $\mathrm{TiO}_{2}$ powder was added to the cuvettes containing $3 \mathrm{~mL}$ of a solution of methylene blue ( $1 \mathrm{mg} / \mathrm{L})$. The solution was sonicated for $1 \mathrm{~min}$, centrifuged and the initial absorbance $\left(A_{0}\right)$ was measured in air (T80 UV/VIS Spectrometer, PG Instruments Ltd) at 20 min intervals until a stable value was reached. Subsequently the samples were irradiated with an UV 
lamp (Helios Quartz 36 W TRIWOOD mod.6/36) placed $10 \mathrm{~cm}$ above them and compared with the control (MB without $\mathrm{TiO}_{2}$ powder). At 20 min intervals the solution was taken, centrifuged and the absorbance $(A)$ measured. The results were normalized to the initial value $A_{0}$.

\section{Results and discussion}

Figure 1 shows the XRD patterns of the $\mathrm{TiO}_{2}$ powders treated at different calcination temperatures. The attribution of the peak positions was made in accordance to the JCPDS cards No. 21-1272 and 21-1276 for anatase (A) and rutile $(R)$, respectively. The spectra of the powder treated at $\mathrm{T}=100^{\circ} \mathrm{C}$ show the presence of broad peaks (low structural order) attributed to anatase phase. At T $=450^{\circ} \mathrm{C}$ the peaks appear better defined and narrower (the increase of temperature improves the crystallization), and we continue to observe the dominance of anatase phase.

At highest temperature $\mathrm{T}=800{ }^{\circ} \mathrm{C}$ the situation radically changed and we observe the anatase to rutile phase transformation, since $T$ acts on the chemical and structural properties of $\mathrm{TiO}_{2}$.

The trend of the phase content as a function of the calcinated temperature was calculated using the Spurr equation [16], considering the integrated intensities of the diffraction peaks of anatase (101) and rutile (110) at 2theta of 25.5 and 27.6 degree, respectively:

$W_{A}=\frac{1}{1+1.26 \frac{I_{(110)}}{I_{A(101)}}} \times 100$

where $W_{\mathrm{A}}$ is the weight fraction in percentage of anatase in the $\mathrm{TiO}_{2}$ powder.

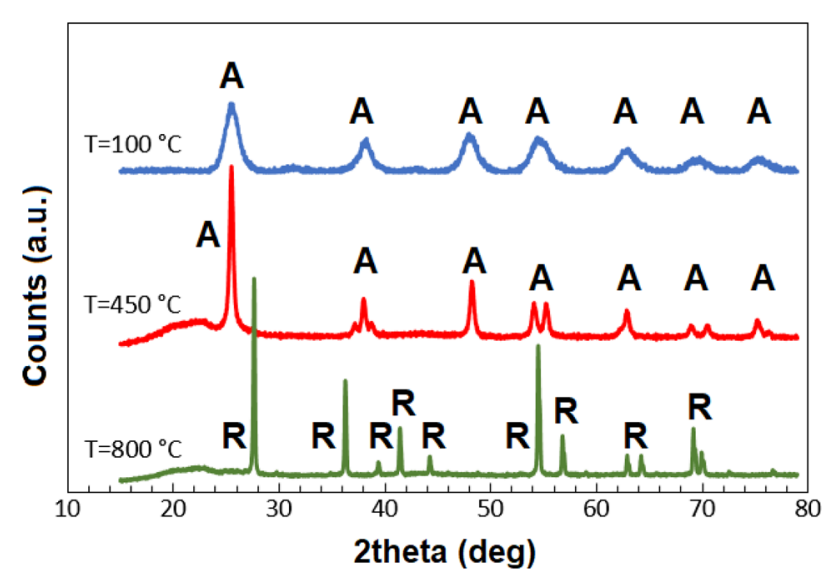

Fig. 1 XRD spectra recorded for the $\mathrm{TiO}_{2}$ powders treated at the calcination temperatures of 100,450 and $800{ }^{\circ} \mathrm{C}$. The letters $A$ and $R$ indicate the anatase and rutile phases, respectively

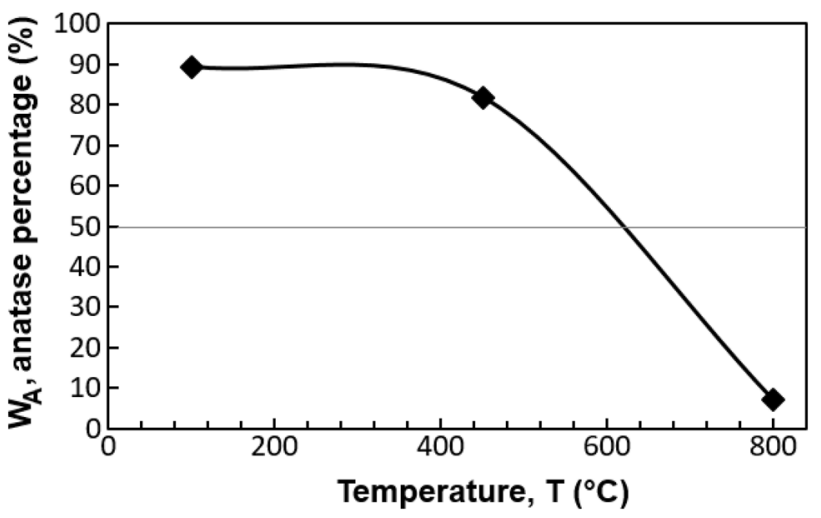

Fig. 2 Trend of weight fraction in percentage $\left(W_{A}\right)$ of anatase for the $\mathrm{TiO}_{2}$ powders as a function of the calcination temperature $(\mathrm{T})$

Figure 2 shows the trend of $W_{\mathrm{A}}$ as a function of the calcination temperature. It is easy to observe that the rutile phase starts to dominate at temperatures higher than $600{ }^{\circ} \mathrm{C}$, in accordance with what is usually observed and reported in literature [17].

Figure 3 reports the Raman spectra of the powders treated at different calcination temperatures. In accordance with XRD analyses, the spectra related to the powders treated at 100 and $450{ }^{\circ} \mathrm{C}$ show four characteristic active modes of the anatase phase. These are observed at 151, $403,518,639 \mathrm{~cm}^{-1}$ for the powder treated at $100^{\circ} \mathrm{C}$ and at $144,397,516,636 \mathrm{~cm}^{-1}$ for that at $450{ }^{\circ} \mathrm{C}$, and are attributed [18] to the vibration symmetries $E_{g^{\prime}} B_{1 g}, A_{1 g} / B_{1 g}$ and $\mathrm{E}_{\mathrm{g}}$, respectively.

On the contrary, the Raman spectrum of the powder calcinated at $800^{\circ} \mathrm{C}$ shows three optical phonon peaks of the rutile phase: a very low-intensity mode centred at $143 \mathrm{~cm}^{-1}$ and two high-intensity modes at 446 and

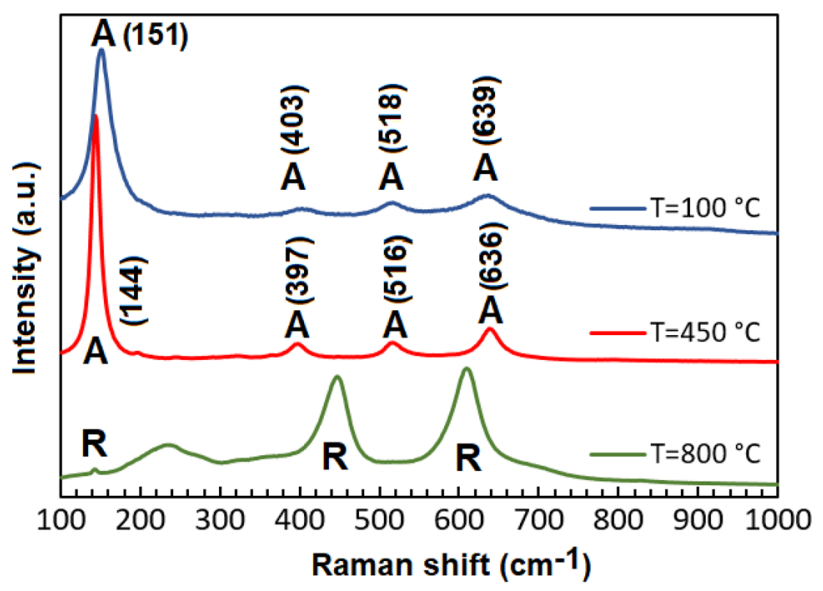

Fig. 3 Raman spectra of $\mathrm{TiO}_{2}$ powders for different calcination temperatures of 100,450 and $800{ }^{\circ} \mathrm{C}$. The letters $A$ and $R$ indicate the anatase and rutile phases, respectively 
$609 \mathrm{~cm}^{-1}$, related to the $B_{1 \mathrm{~g}} \mathrm{E}_{\mathrm{g}}$ and $\mathrm{A}_{1 \mathrm{~g}}$ symmetries, respectively. The band observed around $235 \mathrm{~cm}^{-1}$ is generally attributed to the two-photon scattering [19]. In Fig. 3, it is possible to observe the shift of the $E_{g}$ symmetry of the anatase powders, from 151 to $144 \mathrm{~cm}^{-1}$ at the rise of the temperature. The position of this peak depends on the stoichiometric ratio $\mathrm{O} / \mathrm{Ti}$ [20] and is correlated to the crystalline size and the micro-strains [21] of the $\mathrm{TiO}_{2}$ nanoparticles. A wavenumber shift could be correlated with a crystallite size modification, a change of micro-strain and defects [22].

The Williamson-Hall method [23] was used to determinate the size of the $\mathrm{TiO}_{2}$ nanoparticles by XRD spectra. The total broadening $\beta$ of a diffraction peak is given by the well-known equation

$\beta \cos \theta=\frac{k \lambda}{D}+4 \varepsilon \sin \theta$

where $\theta$ is the Bragg angle, $k$ the Scherrer constant (related to the grains shape), $\lambda=0.154 \mathrm{~nm}$ the $X$-ray wavelength and $\varepsilon$ the strain. The diameter $D$ was determined by the plot of $\beta \cos \theta$ versus $4 \sin \theta$. Figure 4 reports the values of the average $D$ (expressed in $\mathrm{nm}$ ) calculated for the $\mathrm{TiO}_{2}$ powders treated at different calcination temperature $T$.

It is evident that the particle size depends strongly by the calcination temperature and increases at the rise of the calcination temperature. The temperature increase induces the anatase-to-rutile phase transformation (as shown in Fig. 2) and it is often accompanied by a growth of the nanoparticle grain size $[24,25]$.

The photoluminescence spectra of the $\mathrm{TiO}_{2}$ powders obtained at room temperature (excitation $\lambda=375 \mathrm{~nm}$ i.e. $3.31 \mathrm{eV}$ ) are shown in Fig. 5. The PL processes are known to be strongly affected by different factors such as bulk and surface defects, particle size, calcination temperature, excitation wavelength and so on. Moreover, the indirect transition nature of this material [26] makes difficult to

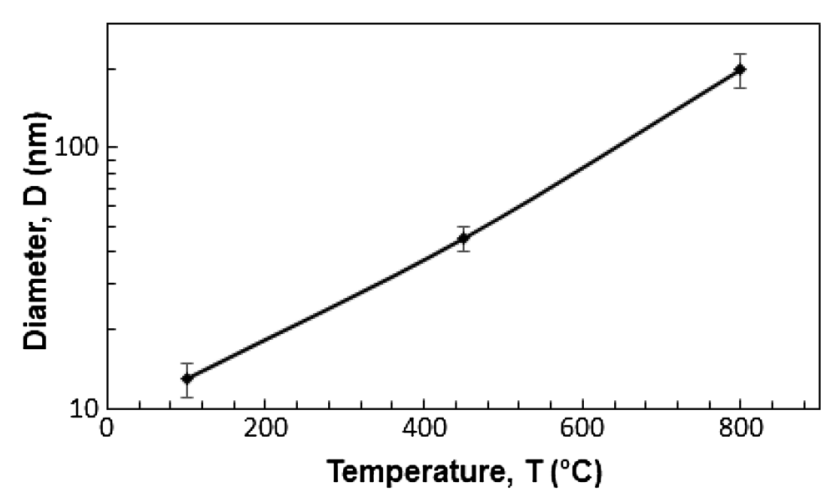

Fig. 4 Average diameters (D) of $\mathrm{TiO}_{2}$ nanoparticle as a function of the calcination temperature $(\mathrm{T})$

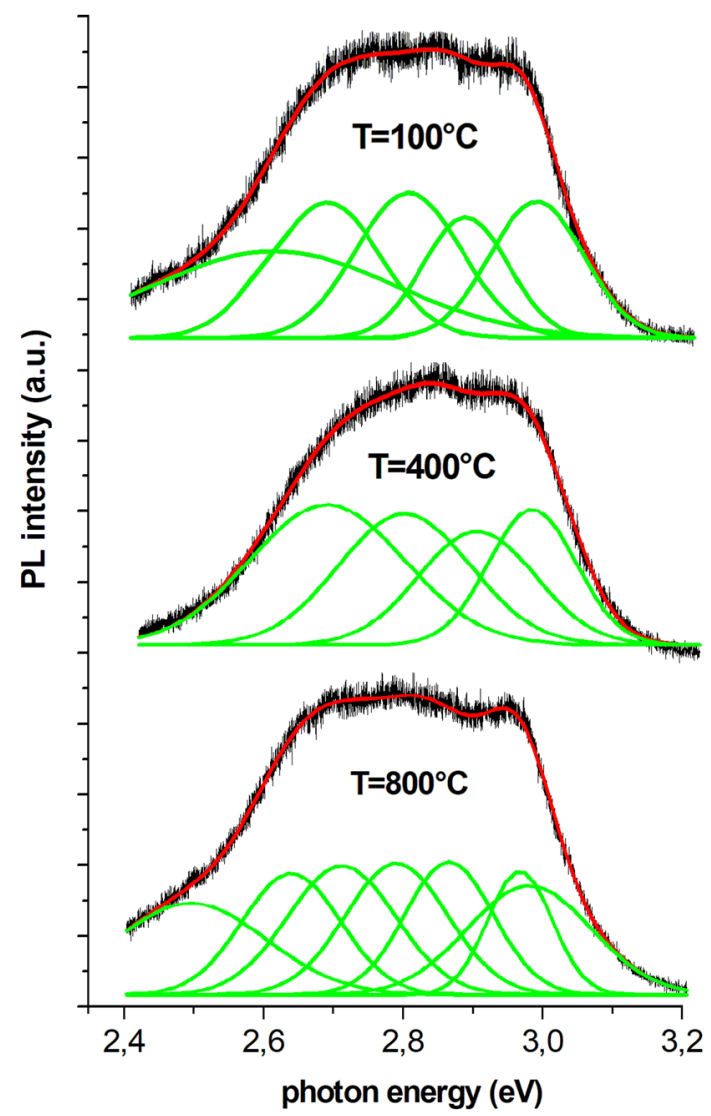

Fig. 5 Photoluminescence (PL) spectra of $\mathrm{TiO}_{2}$ powders treated at different calcination temperature. The red line represents the best fit, the green curves are the peaks obtained by deconvolution

observe the $\mathrm{PL}$ emission at room temperature of the $\mathrm{TiO}_{2}$; indeed the signal quality is not optimal for our spectra.

All the spectra show a broad band centred around $2.8 \mathrm{eV}$. The spectra related to the anatase powders $(T=100$ and $400^{\circ} \mathrm{C}$ ) are very similar whereas the spectrum of the powder treated at $800^{\circ} \mathrm{C}$ shows a larger band, due to its different crystalline phase, that is rutile. In particular, we observed for the rutile powder a higher emission in the spectral range of 2.4-2.6 eV, attributed in other papers [27] to PL from $\mathrm{TiO}_{2}$ surface states. To better known the involved transitions, we made a spectrum deconvolution using Origin software. The red line represents the best-fit whereas the green curves are the deconvoluted peaks. We found five and four peaks for the spectra at 100 and $400^{\circ} \mathrm{C}$, respectively, and seven peaks for the spectrum at $800^{\circ} \mathrm{C}$.

The PL emission bands with tentative assignments, reported in the following discussion, are based on calculations by Daude et al. [28].

For the anatase samples we observed the shallow trap levels corresponding to energies of 2.80 and $2.70 \mathrm{eV}$. The trap level at $2.60 \mathrm{eV}$ is present only in the sample treated at $100{ }^{\circ} \mathrm{C}$. The $\mathrm{PL}$ peak at $2.91 \mathrm{eV}$ corresponds to the 
Table 1 Relative absorbance $\mathrm{A} / \mathrm{A}_{0}$ as a function of the UV-radiation exposure time (measured at 20 min intervals) for the $\mathrm{TiO}_{2}$ powders treated at different calcination temperatures $\left(100,450\right.$ and $\left.800^{\circ} \mathrm{C}\right)$

\begin{tabular}{lllll}
\hline Time (min) & \multicolumn{4}{l}{ Relative absorbance $\mathrm{A} / \mathrm{A}_{0}$} \\
\cline { 2 - 5 } & Control & $100{ }^{\circ} \mathrm{C}$ & $450{ }^{\circ} \mathrm{C}$ & $800^{\circ} \mathrm{C}$ \\
\hline 0 & 1.00 & 1.00 & 1.00 & 1.00 \\
20 & 0.99 & 0.80 & 0.66 & 0.86 \\
40 & 0.99 & 0.71 & 0.53 & 0.77 \\
60 & 0.99 & 0.62 & 0.44 & 0.69 \\
80 & 1.00 & 0.56 & 0.37 & 0.63 \\
100 & 1.00 & 0.51 & 0.32 & 0.59 \\
\hline
\end{tabular}

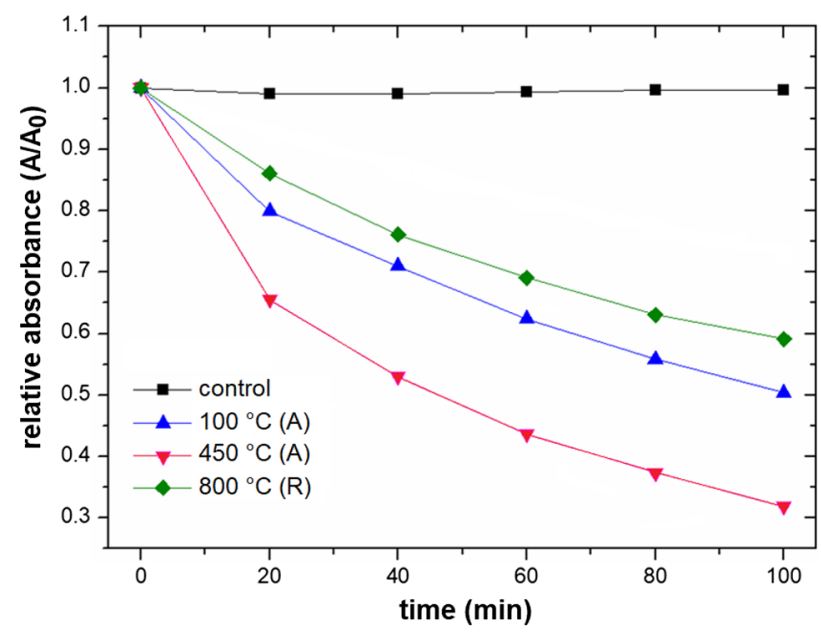

Fig. 6 Photocatalytic degradation of Methylene Blue versus time, obtained with the three $\mathrm{TiO}_{2}$ powders. The letters $\mathrm{A}$ and $\mathrm{R}$ indicate the anatase and rutile phases, respectively

lowest indirect transition (due to the recombination of self-trapped or free excitons $[29,30]$ ) and was observed in the samples treated at $450^{\circ} \mathrm{C}$. The peaks at 2.86 (only at $\mathrm{T}=100^{\circ} \mathrm{C}$ ) and $2.97 \mathrm{eV}$ could be attributed to phonon replica of free excitions [30].

The deconvoluted peaks related to the sample treated at the highest temperature of $800^{\circ} \mathrm{C}$ revealed four peaks due to the shallow trap levels, three at 2.79, 2.71 and $2.63 \mathrm{eV}$ (similar energies were found in anatase powders) and another peak at $2.50 \mathrm{eV}$. As observed in anatase powders, the peaks at $2.86,2.96$ and $2.98 \mathrm{eV}$ are probably due to phonon replicas of free excitons [30].

Table 1 reports the values of the relative absorbance $A / A_{0}$ (measured during the $M B$ degradation tests) as a function of the UV-radiation exposure time (20 min intervals) for the $\mathrm{TiO}_{2}$ powders treated at different calcination temperatures.

Figure 6 shows the curves related to the photocatalytic degradation of methylene blue for the $\mathrm{TiO}_{2}$ powders, obtained by the values reported in Table 1 . The control test shows no obvious degradation of MB under UV irradiation. The trends of the two anatase powders ( $T=100$ and $450^{\circ} \mathrm{C}$ ) show a better photocatalytic activity with respect the rutile one $\left(T=800^{\circ} \mathrm{C}\right)$. This result confirms what is generally reported in the literature: the increase of the calcination temperature induces the transformation phase from anatase to rutile (the most stable phase of $\mathrm{TiO}_{2}$ ) but causes a significant reduction in photocatalytic activity [31-33]. The electron-hole recombination is known to be faster in rutile with a low electron mobility $[34,35]$ : as result, the photocatalytic activity of anatase is better with respect rutile.

The comparison between the two anatase powders evidences a better relative absorbance for that treated at $450^{\circ} \mathrm{C}$. Despite the larger average size of the nanoparticles which decreases the active surface area to volume ratio, the $\mathrm{TiO}_{2}$ powder treated a $450^{\circ} \mathrm{C}$ shows a better photocatalytic activity. As observed by Baiju et al. [36], this behaviour could be associated to the existence of a critical size of titania nanoparticles ( $D \sim 15 \mathrm{~nm}$ ), below and above which the photocatalytic activity is observed to be reduced.

\section{Conclusions}

In conclusion, this work has shown how the calcination temperature influences the phase composition, the degree of crystallinity, the nanoparticle dimension, the optical properties and the photocatalytic activity of $\mathrm{TiO}_{2}$ powders produced by sol-gel method. The obtained results have shown that the increase of temperature induces the rise of the grain size of $\mathrm{TiO}_{2}$ nanoparticles and causes the phase transformation from anatase to rutile. Moreover, it is interesting to notice how rutile (obtained at $800^{\circ} \mathrm{C}$ ) even thought is known to be the most stable phase of $\mathrm{TiO}_{2}$ exhibits the lowest photocatalysis compared to anatase powders $\left(100\right.$ and $450^{\circ} \mathrm{C}$ ), due to the higher recombination of photo-generated electrons and holes of rutile with respect to anatase.

\section{Compliance with ethical standards}

Conflict of interest The authors declare that they have no conflict of interest.

\section{References}

1. Fujishima A, Honda K (1972) Electrochemical photolysis of water at a semiconductor electrod. Nature 238:37 
2. Lan Y, Lu Y, Ren Z (2013) Mini review on photocatalysis of titanium dioxide nanoparticles and their solar applications. Nano Energy 2:1031

3. Ito $S$, Zakeeruddin S, Humphry-Baker R, Liska P, Charvet R, Comte P, Nazeeruddin M, Péchy P, Takata M, Miura H, Uchida S, Grätzel M (2006) High-efficiency organic-dye-sensitized solar cells controlled by nanocrystalline- $\mathrm{TiO}_{2}$ electrode thickness. Adv Mater 18:1202

4. Liu Y, Zhou B, Bai J, Li J, Zhang J, Zheng Q, Zhu X, Cai W (2009) Efficient photochemical water splitting and organic pollutant degradation by highly ordered $\mathrm{TiO}_{2}$ nanopore arrays. Appl Catal B 89:142

5. Yu JC, Ho W, Lin J, Yip H, Wong PK (2003) Photocatalytic activity, antibacterial effect, and photoinduced hydrophilicity of $\mathrm{TiO}_{2}$ films coated on a stainless steel substrate. Environ Sci Technol 37:2296

6. Scrimieri L, Serra A, Manno D, Alifano P, Tredici SM, Calcagnile $\mathrm{M}$, Calcagnile $\mathrm{L}$ (2019) $\mathrm{TiO}_{2}$ films by sol-gel spin-coating deposition with microbial antiadhesion properties. Surf Interface Anal 51:1351-1358

7. Delle Side D, Nassisi V, Giuffreda E, Velardi L, Alifano P, Talà A, Tredici SM (2014) Highly antibacterial UHMWPE surfaces by implantation of titanium ions. Nucl Instrum Methods Phys Res Sect B 331:172. https://doi.org/10.1016/j.nimb.2013.11.027

8. Delle Side D, Nassisi V, Giuffreda E, Velardi L, Alifano P, Talà A, Tredici SM (2014) Antibacterial properties of composite UHMWPE/TiO ${ }_{2-x}$ surfaces. Appl Phys A 117:191

9. Guan K (2005) Relationship between photocatalytic activity, hydrophilicity and self-cleaning effect of $\mathrm{TiO}_{2} / \mathrm{SiO}_{2}$ films. Surf Coat Technol 191:155

10. Kim DJ, Hahn SH, Oh SH, Kim EJ (2002) Influence of calcination temperature on structural and optical properties of $\mathrm{TiO}_{2}$ thin films prepared by sol-gel dip coating. Mater Lett 57:355

11. Kalaivani T, Anilkumar P (2018) Role of temperature on the phase modification of $\mathrm{TiO}_{2}$ nanoparticles synthesized by the precipitation method. Silicon 10:1679

12. Wetchakun N, Phanichphant S (2008) Effect of temperature on the degree of anatase-rutile transformation in titanium dioxide nanoparticles synthesized by the modified sol-gel method. Curr Appl Phys 8:343

13. Henderson MA (2011) A surface science perspective on $\mathrm{TiO}_{2}$ photocatalysis. Surf Sci Rep 66:185. https://doi. org/10.1016/j.surfrep.2011.01.001

14. Pelaez M, Nolan NT, Pillai SC, Seery MK, Falaras P, Kontos AG, Dunlop PSM, Hamilton JWJ, Byrne JA, O'Shea K, Entezari MH, Dionysiou DD (2012) A review on the visible light active titanium dioxide photocatalysts for environmental applications. Appl Catal B 125:331

15. Grzechulska J, Morawski AW (2002) Photocatalytic decomposition of azo-dye acid black 1 in water over modified titanium dioxide. Appl Catal B 36:45

16. Spurr RA, Myers H (1957) Quantitative analysis of anatase-rutile mixtures with an X-ray diffractometer. Anal Chem 29:760

17. Negishi N, Takeuchi K (1999) Structural changes of transparent $\mathrm{TiO}_{2}$ thin films with heat treatment. Mater Lett 38:150

18. Ma W, Lu Z, Zhang M (1998) Investigation of structural transformations in nanophase titanium dioxide by Raman spectroscopy. Appl Phys A 66:621

19. Challagulla S, Tarafder K, Ganesan R, Roy S (2017) Structure sensitive photocatalytic reduction of nitroarenes over $\mathrm{TiO}_{2}$. Sci Rep 7:8783

20. Parker JC, Siegel RW (1990) Calibration of the Raman spectrum to the oxygen stoichiometry of nanophase TiO2. Appl Phys Lett 57:943
21. Golubović $A$, Šćepanović $M$, Kremenović $A$, Aškrabić $S$, Berec V, Dohčević-Mitrović Z, Popović ZV (2009) Raman study of the variation in anatase structure of $\mathrm{TiO}_{2}$ nanopowders due to the changes of sol-gel synthesis conditions. J Sol-Gel Sci Technol 49:311

22. Shao Y, Tang D, Sun J, Lee Y, Xiong W (2004) Lattice deformation and phase transformation from nano-scale anatase to nanoscale rutile $\mathrm{TiO}_{2}$ prepared by sol-gel technique. China Part 2:119

23. Williamson GK, Hall WH (1953) X-ray line broadening from filed aluminium and wolfram. Acta Metall 1:22

24. Bakardjieva S, Subrt J, Stengl V, Dianez MJ, Sayagues MJ (2005) Photoactivity of anatase-rutile $\mathrm{TiO}_{2}$ nanocrystalline mixtures obtained by heat treatment of homogeneously precipitated anatase. Appl Catal B 58:193

25. Gnaser H, Lösch J, Orendorz A, Ziegler C (2011) Temperaturedependent grain growth and phase transformation in mixed anatase-rutile nanocrystalline $\mathrm{TiO}_{2}$ films. Phys Status Solidi A 208:1635

26. Chiodo L, García-Lastra JM, lacomino A, Ossicini S, Zhao J, Petek $H$, Rubio A (2010) Self-energy and excitonic effects in the electronic and optical properties of $\mathrm{TiO}_{2}$ crystalline phases. Phys Rev B 82:045207

27. Rahman NM, Krishna KM, Soga T, Jimbo T, Umeno M (1999) Optical properties and X-ray photoelectron spectroscopic study of pure and $\mathrm{Pb}$-doped $\mathrm{TiO}_{2}$ thin films. J Phys Chem Solids 60:201

28. Daude N, Gout C, Joouanin C (1977) Electronic band structure of titanium dioxide. Phys Rev B 15:3229

29. Saraf LV, Patil SI, Ogale SB, Sainkar SR, Kshirsager ST (1998) Synthesis of nanophase $\mathrm{TiO}_{2}$ by ion beam sputtering and cold condensation technique. Int J Mod Phys B 12:2635

30. Kernazhitsky L, Shymanovska V, Gavrilko T, Naumov V, Fedorenko L, Kshnyakin V, Baran J (2014) Room temperature photoluminescence of anatase and rutile $\mathrm{TiO}_{2}$ powders. J Lumin 146:199

31. Yu JG, Yu HG, Cheng B, Zhao XJ, Yu JC, Ho W-K (2003) The effect of calcination temperature on the surface microstructure and photocatalytic activity of $\mathrm{TiO}_{2}$ thin films prepared by liquid phase deposition. J Phys Chem B 107:13871

32. Tanaka Y, Suganuma M (2001) Effects of heat treatment on photocatalytic property of sol-gel derived polycrystalline $\mathrm{TiO}_{2}$. J SolGel Sci Technol 22:83

33. Li D, Cheng X, Yu X, Xing Z (2015) Preparation and characterization of $\mathrm{TiO}_{2}$-based nanosheets for photocatalytic degradation of acetylsalicylic acid: influence of calcination temperature. Chem Eng J 279:994

34. Sun B, Vorontsov AV, Smirniotis G (2003) Role of platinum deposited on $\mathrm{TiO}_{2}$ in phenol photocatalytic oxidation. Langmuir 19:3151

35. Luís AM, Neves MC, Mendonca MH, Monteiro OC (2011) Influence of calcination parameters on the $\mathrm{TiO} 2$ photocatalytic properties. Mater Chem Phys 125:20

36. Baiju KV, Shukla S, Sandhya KS, James J, Warrier KGK (2007) Photocatalytic activity of sol-gel-derived nanocrystalline titania. J Phys Chem C 111:7612

Publisher's Note Springer Nature remains neutral with regard to jurisdictional claims in published maps and institutional affiliations. 